УДК 72.036(438)"195"

ББК 85.113(4Пол)63,003

\title{
Е.М. КУЗЮРИНА
}

\section{АРХИТЕКТУРА НАРОДНОЙ ПОЛЬШИ КАК ОТРАЖЕНИЕ ПОЛИТИЧЕСКИХ ИДЕЙ}

Евгения Михайловна Кузюрина,

Сыктывкарский государственный университет

им. П. Сорокина,

кафредра культурологии и педагогической антропологии, аспирант

Октябрьский просп., д. 55,

Сыктывкар, Республика Коми, 167001, Россия

E-mail: evgeniya.kuzurina@gmail.com

Реферат. В статье предлагается концепиия архитектуры как способа презентации политических идей посредством эстетических категорий на основе анализа социалистических сооружений: Дворияа культуры и науки в Варшаве и Новой Гуты. Предмет исследования настоящей статьи - функции архитектуры в презентации идеологии политического режима Народной Польши.

Вопрос политизированности искусства, в том числе архитектуры, остается актуальным и на современном этапе, когда проблема политического манипулирования по-прежнему широко распространена в обществе. Среда, организуемая архитектурой, также постоянно воздействует на эмоции, сознание и поведение человека. Становится возможной передача заранее программируемой информачии через архитектурные сооружения.

Предмет исследования указывает на необходимость междисииплинарного подхода. Методологическую основу исследования планируется выстроить, опираясь на сравнительный, проблемно-хронологический, семиотический методы, искусствоведческий и системный анализ.

Архитектура Народной Польши в статье представлена в виде особого социально-политического пространства, которое незамедлительно перекодируется в зависимости от смены режима. Это выражается в переименовании улии и площадей, в замене мировых героев национальными и пр. С установлением коммунистического режима в Польше в культуру был внедрен принщи социалистического реа- лизма, искусство было подчинено потребностям идеологии и политики. Подробно исследуется роль архитектурного строительства Народной Польши в изменении структуры общества. Затронуты также вопросы отношения к наследию эпохи социалистического реализма в современной Польше, которое оценивается неоднозначно.

В заключение делается вывод, что архитектура отражает историко-культурологический контекст, является интерпретацией политического и социального процессов в пространстве.

Ключевые слова: эстетика, политика, политическая эстетика, архитектура, Новая Гута, Дворец культуры и науки, социалистический реализм.

Для цитирования: Кузюрина E.M. Архитектура Народной Польши как отражение политических идей // Обсерватория культуры. 2017. Т. 14, № 2. C. $240-246$.

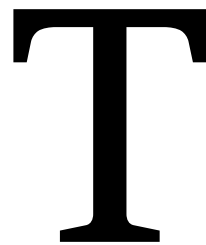

ермин «политическая эстетика» может быть полезным при изучении использования эстетических параметров в политических целях. В частности, как разновидность политической эстетики может быть интерпретирован социалистический реализм.

Архитектура представляет собой особое социально-политическое пространство, которое не в меньшей мере, чем другие виды искусства зависит от идеологических установок. Ряд признаков архитектуры позволяет рассматривать этот вид искусства с точки зрения политической эстетики, как способа репрезентации политических идей посредством эстетических категорий. Архитектура обладает способностью организовывать пространство для определенной социально значимой цели. Отсюда возможность передачи заранее программируемой информации через архитектурные сооружения. Данная информации важна для формирования психологических установок и воспитания личности. Архитектура, что важно для политической эстетики, 


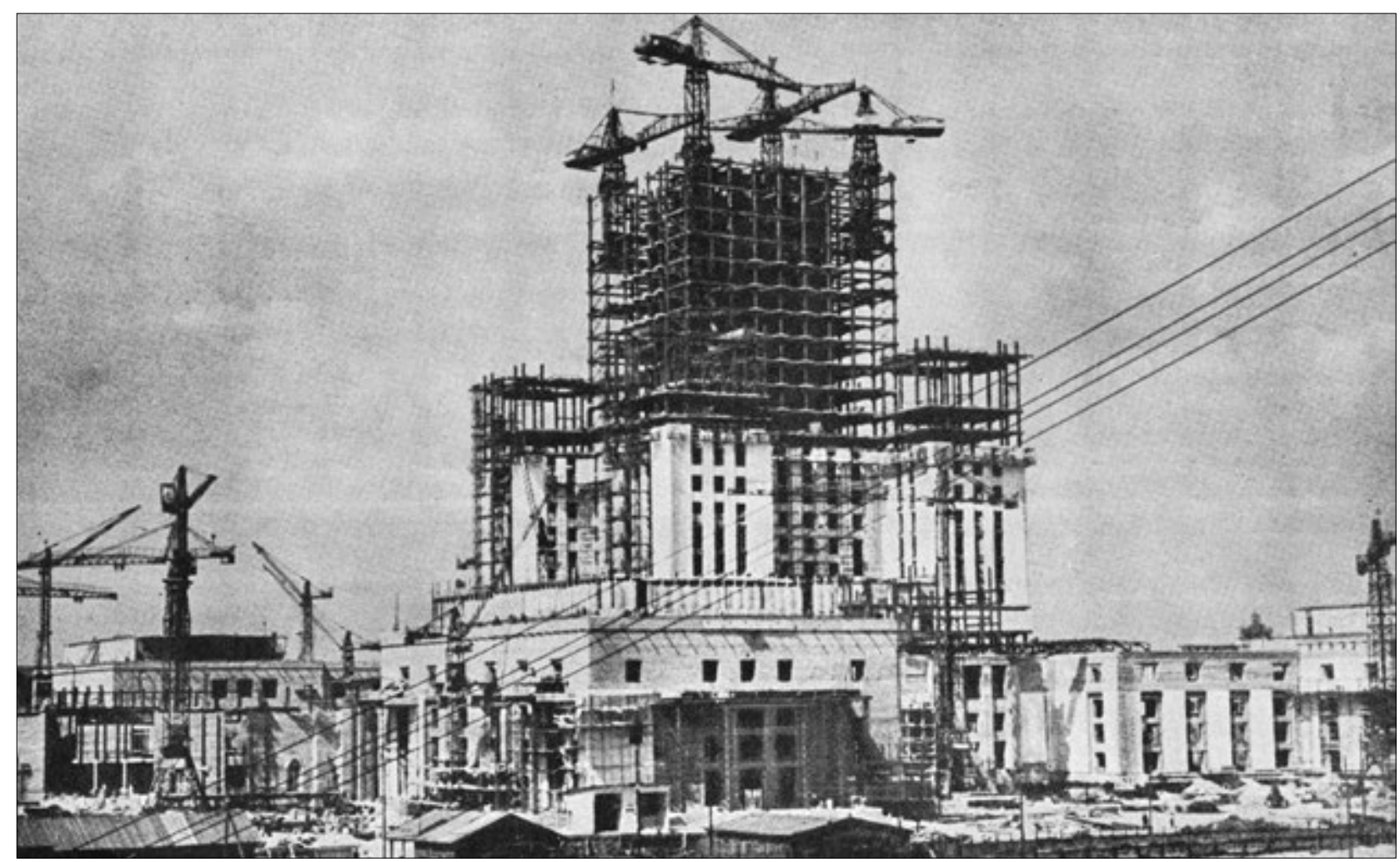

Строительство Дворца культуры и науки

обладает двоякой ценностью - материально-практической и информационно-эстетической [1, с. 6].

Как отмечает искусствовед А.В. Иконников, архитектура стала одним из важнейших средств утверждения идеологий. Например, В.И. Ленин называл архитектуру «монументальной пропагандой» [2]. В ней опредмечиваются мировоззрение общества, его этические принципы и эстетические идеалы. Среда, организованная архитектурой, всегда ненавязчиво, но постоянно воздействует на эмоции, сознание и поведение человека. Эстетическое, таким образом, выступает как некая «надстройка», а создание эстетических ценностей - необходимая часть общественного назначения архитектуры [1, с. 7].

Наиболее яркий образ коммунистического периода в Польше создают два совершенно разных по своему функциональному назначению объекта. Это Дворец культуры и науки в Варшаве и Новая Гута, район, построенный недалеко от Кракова. Подобная архитектура направлена, по определению P. Смита и В. Бани, на содействие социальным переменам и поддержание определенного образа мышления [3, с. 75].

Относительно целей строительства Новой Гуты, которое началось в 1949 г., существует несколько точек зрения. Одни исследователи в первую очередь говорят о стремлении новой власти искусственно изменить социальную структуру Кракова: разбавить буржуазный и католический регион представителями рабочего класса, ограничив влияние краковской интеллигенции [4]. Для этих целей будущих рабочих специально переселяли из деревень. Предполагалось, что город со временем сможет поглотить древнюю польскую столицу [5]. Новая Гута была первым социалистическим городом в Польше, в котором к тому же не было костела.

Архитектурное строительство Новой Гуты может быть рассмотрено с точки зрения градостроительной концепции «социалистического города», которая по мнению искусствоведа С.О. Хан-Магомедова была наиболее полно изложена в 19291930 гг. в теоретических работах экономиста Л. Сабсовича. Основа социалистического расселения заключалась в создании ограниченных по размерам компактных поселений при крупных промышленных предприятиях и совхозах. Соцгорода должны были отличаться от капиталистических городов по своим размерам, принципам культурнобытового обслуживания, организации быта их жителей [6]. По сути, идеи концепции «соцгорода» заключались в создании как материальной базы для социалистической экономики, так и новых общественных отношений. Новая Гута удовлетворяет всем требованиям соцгорода: поселение вокруг металлургического комбината, возведение которого было связано с шестилетним планом строительства основ социализма в Польше (1950-1955). Основ- 
ными задачами плана были послевоенное восстановление страны и ее индустриализация.

Аналогом Новой Гуты в СССР называют Комсомольск-на-Амуре. Оба города были новостройками, созданными по принципам социалистического реализма, основную массу их строителей составляла молодежь. Отсюда и название, употребляемое по отношению к ним - «города юности» [7, с. 21].

Что касается Дворца науки и культуры в Варшаве, то он возводился в качестве подарка советского народа польскому. Дворец должен был стать не только пространственным ориентиром - самым высоким зданием в городе, но и эталоном стиля [8]. Он считается «родственником» сталинских высотных зданий, строительство которых в Москве ознаменовало послевоенный триумф режима [9]. Особое значение Дворцу как атрибуту образцовой социалистической столицы придавал тот факт, что в 1955 г., после заключения Варшавского договора, столица Польши обрела номинальный статус столицы стран восточного блока.

При реализации обоих проектов в духе социалистического реализма был предложен комплексный подход. Дворец стал многофункциональной культурной точкой столицы. После окончания строительства в здании были размещены театры, выставочные и концертный залы, Музей техники, Академия наук.

При строительстве Новой Гуты одновременно велось планирование жилищного строительства, транспортной инфраструктуры, магазинов, рабочей зоны (в данном случае завода) и, конечно, центральной площади, которая стала местом проведения манифестаций и парадов. План города представляет собой «веер»: несколько главных улиц начинаются от центральной площади и расходятся в разные стороны [10]. Они получили названия в духе коммунистической идеологии: Аллея Октябрьской революции, Аллея Шестилетнего плана, Аллея Кубинской революции, Аллея Ленина (изначально - Аллея ударников труда), которая соединяла Центральную площадь и металлургический комбинат.

Управленческие здания были сосредоточены вокруг центральной площади. Городские артерии обозначали «ось комбината», связанную с работой, и «центральную ось», где была сосредоточена административная, политическая и социальная жизнь города. Две оставшиеся артерии выполняли коммуникационные функции [10].

Большое влияние на строительство оказал Союз Советских Социалистических Республик. И хотя главным архитектором Новой Гуты был поляк Т. Пташицкий, все чертежи и оборудование, по воспоминаниям Ю. Циранкевича - бывшего Председателя Совета министров Польши, предоставлялись из СССР [11, с. 5].

Дворец проектировал советский архитектор Л.В. Руднев, среди работ которого уже был Москов- ский государственный университет им. М.В. Ломоносова на Ленинских горах. Форма здания университета должна была стать образцом для варшавской новостройки [12].

Здание представляет собой своеобразную смесь стилей: ар-деко, соцреализма и польского историзма. В 1951 г. советские архитекторы по приглашению польского руководства посетили несколько городов для изучения национальной архитектуры страны. Культуролог М. Стрельбицкая отмечает, что при строительстве Дворца были использованы архитектурные детали, схожие с аттиками Сукенниц в Кракове и городского рынка в Казимеже над Вислой, завершение (шпиль) Дворца перекликается с композицией ратуши [12]. К сожалению, в историографии не удалось найти сведений о том, идет ли речь о конкретной ратуше или просто о принципах сооружения этих зданий. Шпиль является характерным элементом сталинских высоток (его завершение - пятиконечная звезда). В украшении фасада здания были использованы монументальные скульптуры, в частности изображающие А. Мицкевича, Н. Коперника и 28 соцреалистических скульптур советских авторов: аллегории планового хозяйства, науки, искусства, спорта, металлургии [13].

Стиль застройки Новой Гуты, напротив, достаточно лаконичен. Здесь нет мозаик, витражей, мало рельефов и скульптур. Город напоминает провинциальные советские социалистические города. Проектировщики Новой Гуты использовали элементы классицизма, что было связано с желанием провести параллель с Краковом [4]. В 1951 г. завод, градообразующее предприятие, был назван именем В.И. Ленина, а поскольку коммунистический ритуал требовал возложения делегациями цветов к памятному месту, в Новой Гуте в 1973 г. был открыт и памятник В.И. Ленину. Несмотря на усилия властей, памятник стал объектом шуток и вульгарных комментариев, а в 1979 г. был взорван. С падением коммунистического режима в декабре 1989 г. памятник демонтировали [14]. В настоящее время переименован и металлургический комбинат. Теперь он носит имя известного в Польше металлурга Т. Сендзимира. Были изменены и названия улиц. Например, бывшая улица Ленина получила название Аллея Солидарности, Аллея Октябрьской революции - имя генерала В. Андерса, после войны занимавшего враждебную позицию к коммунистической власти. Еще раньше, при включении Новой Гуты в состав Кракова в 1951 г., Аллея Шестилетнего плана и Аллея Кубинской революции стали частью Аллеи Иоанна Павла II, соединяющей Краков с Центральной площадью Новой Гуты. Сама же Центральная площадь в 2004 г. получила имя бывшего Президента США P. Рейгана, известного своей жесткой антикоммунистической позицией. Подобные изменения отразили новые политические ориентиры страны. 
В настоящее время Новую Гуту считают местом «борьбы против репрессивной государственной системы» [15]. Жители «образцового города» еще в 1960 г. добивались разрешения на строительство храма, а с 1981 г. регулярно организовывали забастовки и уличные акции протеста [16]. Уже в середине 1950-х гг. стало ясно, что город был далек от заявленного «идеала». Жизненный уровень населения был низким, наблюдалась регрессия социального и культурного развития [17].

На сегодняшний день Новая Гута, как один из районов Кракова, представляет собой многоплановый культурно-общественный объект. В начале 2000-х гг. молодые художники, реализуя в Новой Гуте различные арт-проекты, стремились превратить депрессивный район в пространство современной культуры, в узнаваемый бренд, используя положительные стороны прошлого опыта: культ труда, тесные соседские связи, коллективную деятельность. В 2004 г. был открыт театр, где первые постановки носили ностальгический характер (о местных героях, погибших в борьбе с коммунистическим режимом, о жизни комбината). Стала выходить районная газета, были открыты клуб и кинотеатр. К. Сыска, филолог, сотрудник Ягеллонского университета в Кракове, все эти начинания обозначила термином «соц-ностальгия» [15].

Что касается Дворца, его восприятие поляками оказалось неоднозначным. Польской властью он был принят с благодарностью. На первой полосе газеты «Жизнь Варшавы» («̇̇ycie Warszawy») в день открытия Дворца была помещена фотография здания с надписью: «Спасибо вам, товарищи!» Для местных жителей, по мнению польского руководства, Дворец стал символом дружбы. Выступивший на торжественном открытии Б. Берут, бывший тогда первым секретарем Польской объединенной рабочей партии, подчеркнул, что Дворец культуры - это в первую очередь «символ могучей силы пролетарского интернационализма» [Цит. по: 18].

Здание, в соответствии с планами советской власти, должно было отметить новый этап истории Польши, изменив облик ее столицы, став олицетворением общих социалистических идеалов, осуществляя преемственность с польской культурой [19].

Противники Дворца оценивали присутствие советского «подарка» в пространстве столицы как пример постколониализма и как показатель расширения советской власти за пределами СССР. В современной польской публицистике Дворец оценивается как «символ польского порабощения советской империей», как «наблюдательная вышка в центре социалистического лагеря» [20]. Ассоциативный ряд мог возникнуть в сознании благодаря размерам Дворца, высота которого вместе со шпилем составляет 230,68 метра.
Подобный символический «захват» пространства в Польше уже был, когда в 1918 г. на Саксонской площади в Варшаве был воздвигнут Александро-Невский собор. После завершения строительства собор достигал в высоту 70 м и был в то время также самым высоким зданием в Варшаве. Собор аналогично Дворцу вызывал ассоциации с российским господством над Польшей. Он был разрушен в 1918 г., после обретения Польшей независимости, а площадь переименована в честь маршала Ю. Пилсудского.

Дворец и Собор выделялись в окружающем их пространстве, изначально становились символами подчиненного положения Польши относительно российского, а позднее советского режима. В сознании польского общества сформировалось устойчивое духовное и политическое неприятие архитектурных «подарков».

Дворец на сегодняшний день остается предметом многочисленных споров. В частности, в 2009 г. на следующий день после празднования двадцатой годовщины падения Берлинской стены Р. Сикорский, будучи главой Министерства иностранных дел Польши, высказался за разрушение Дворца как символа коммунизма, на месте которого было предложено разбить парк [20].

Но если сегодня многие представители политической элиты Польши являются противниками сохранения Дворца, то обычные варшавяне, особенно молодежь, демонстрируют положительное к нему отношение. Общественные опросы показывают, что образ столицы даже у противников здания неразрывно ассоциируется с Дворцом. Все чаще характерный силуэт здания используется как метонимия города [21].

Символично, что именно в здании Дворца культуры и науки в 1967 г. выступали «The Rolling Stones» - это было первое шоу за «железным занавесом» рок-группы из капиталистической страны. Позднее, в начале 1990-х гг. из вестибюля Дворца убрали скульптуру польского и советского строителей. С книги, которую держала в руках статуя на фасаде, убрали имя И.В. Сталина. В эти же годы предполагалось снести здание или переоборудовать его под музей. В итоге победил проект, предусматривающий постройку новых небоскребов вокруг Дворца культуры, чтобы уменьшить степень его доминирования в общей панораме столицы.

В 1990 гг. в Польше состоялось несколько дискуссий историков, архитекторов и реставраторов по поводу признания за зданием Дворца культуры и науки статуса памятника истории старины. В 2007 г. Дворец был включен в реестр памятников культуры Польши. Новая Гута, как один из наиболее ярких примеров архитектуры соцреализма в Польше, также была включена в реестр памятников архитектуры. 


\section{$* * *$}

Установление коммунистического режима в Польше отразилось на культуре. Главные изменения были связаны с внедрением принципа социалистического реализма и подчинением искусства потребностям идеологии и политики. Соцреализм составлял сущность политической эстетики Народной Польши в исследуемый период, будучи одновременно способом как организации, так и трансляции политических идей посредством искусства.

В коммунистической Польше политическая эстетика начала испытывать сильное советское влияние. Поляки просто приняли, насколько смогли, и термин, и свойственный социалистическому реализму способ отражения реальности. Исторический контекст и общественные настроения не позволили, однако, полностью отказаться от собственных культурных традиций.

Самыми известными сооружениями этой эпохи стали Дворец культуры и науки в Варшаве и Новая Гута. Назначение, стиль и масштаб новых сооружений свидетельствовали о значительных переменах в стране и обществе. Главной особенностью архитектуры соцреализма была монументальность, которая оказывала подавляющее воздействие на человека.

Архитектурное строительство стало и способом постепенного изменения структуры общества. Новая Гута задумывалась как образцовый социалистический город с идеей доминирования рабочего класса, который должен был стать основой нового общества. Дворец культуры и науки стал не столько символом польской политической элиты, сколько означал развитие по советскому образцу под контролем СССР. Прочная связь с Советским Союзом подчеркивала подчиненное и зависимое положение Народной Польши. В архитектуре как Польши, так и иных социалистических стран прослеживалась тенденция к идеологической и культурной унификации с выраженным влиянием СССР. Здания в стиле сталинских высоток были в описываемый период построены не только в Варшаве, но и в Риге (Академия наук Латвии, 1952-1958 гг.), в Бухаресте (полиграфический комбинат «Дом “Скынтеи” , затем - «Дом свободной прессы», 1952-1956 гг.).

Архитектурные сооружения соответствовали идеологической формуле: социалистическое по содержанию и национальное по форме. В честь советских лидеров устанавливались памятники, давались названия объектам, которые, однако, не сохранялись при новой смене режима.

Наследие эпохи социалистического реализма в современной Польше оценивается неоднозначно. Наряду с негативными оценками, наблюдается тенденция их сохранения в качестве свидетельств данного периода. Однако споры вокруг социалистической архитектуры, напротив, побуждают интерес к прошлому.

\section{Список источников}

1. Иконников А.В. Функция, форма, образ в архитектуре. Москва : Стройиздат, 1986. 286 с.

2. Луначарский А.В. Воспоминания и впечатления. Ленин о монументальной пропаганде, 1933 [Электронный ресурc]. URL: http://leninism.su/memory/4163vospominaniya-i-vpechatleniya.html?showall=\&start=19 (дата обращения: 16.02.2017).

3. Смит Р.В., Бани В. Теория символического интеракционизма и архитектура // Социологические исследования. 2010. № 9. С. 71-79.

4. Веселовская B. «Nowa Huta» в Кракове - (не)забытое прошлое, или Почему популярный среди туристов из EC район не посещают жители стран бывшего СССР. 2014 [Электронный ресурс]. URL: http://www.day. kiev.ua/ru/article/puteshestviya/nowa-huta-v-krakovenezabytoe-proshloe (дата обращения: 02.12.2016).

5. Cegła E. Socrealizm Nowej Huty widzianyz «trabanta». 2013 [Электронный ресурс]. URL: http://krakow. naszemiasto.pl/artykul/galeria/socrealizm-nowej-hutywidziany-z-trabanta,1944421,t,id.html (дата обращения: 02.02.2017). Польск. яз.

6. Хан-Магомедов С.О. Архитектура советского авангарда. Кн. 2: Социальные проблемы. Москва : Стройиздат, 2001. 712 c. URL: http://www.alyoshin.ru/Files/ publika/khan_archi/khan_archi_2_037.html (дата обращения: 10.10.2016).

7. Павлович В. Строители Новой Гуты // Смена. 1953. № 14. C. $21-22$. URL: http://smena-online.ru/ sites/default/files/14_-_1953.pdf (дата обращения: 10.10.2016).

8. Иконников А.В. Архитектура XX века : Утопии и реальность. Т. 1. Москва : Прогресс-Традиция, 2001. 669 с.

9. История «сталинских» высоток и ее продолжение. Фото. Ч. 1. 2007 [Электронный ресурс]. URL: http:// www.archdesignfoto.com/istoriya-stalinskix-vysotoki-ee-prodolzhenie-foto-chast-1.html (дата обращения: 6.02.2017).

10. Стрельбищкая М. Варшава. Шестилетний план реконструкции 1950-1955 гг. // Советская архитектура. URL: http://www.sovarch.ru/104/ (дата обращения: 02.02.2017).

11. Циранкевич Ю. Польша на путях к социализму // Огонек. 1950. № 39. С. 4-5.

12. Стрельбицкая М.В. Дворец Культуры и Науки в Варшаве (Pałac Kultury i Nauki) [Электронный ресурс] // Советская архитектура. Объекты. URL: http://www. sovarch.ru/catalog/object/234/?photo=5 (дата обращения: 25.11.2016).

13. Архитектура и политика. [Интервью с доктором политических наук, профессором М.Ю. Урновым] [Электронный ресурс] // Полит.ру : информационно-аналитический канал. 2010. URL: http://polit.ru/ article/2010/08/24/architechture/1347867610000/ (дата обращения: 02.02.2017).

14. Łaszkiewicz M. O Nowej Hucie słów kilka. Powstanie i rozwój dzielnicy. 2011 [Электронный ресурc]. URL: 
http://www.konflikty.pl/historia/czasy-najnowsze/onowej-hucie-slow-kilka-powstanie-i-rozwoj-dzielnicy/ (дата обращения: 24.10.2016). Польск. яз.

15. Сыска К. Культура, ностальгия, интеллигенция: польский опыт [Электронный ресурс] // Интелрос - интеллектуальная Россия: Международный журнал исследования культуры. 2015. № 4. URL: http://www. intelros.ru/readroom/nz/n4-2015/28090-kulturanostalgiya-intelligenciya-polskiy-opyt.html (дата обращения: 22.11.2016).

16. Nowa Huta - dzieło polskiego socrealizmu. 2014 [Электронный ресурc]. URL: http://www. polskieradio.pl/39/156/Artykul/1154281, Nowa-Huta\%Е2\%80\%93-dzielo-polskiego-socrealizmu (дата обращения: 24.10.2016). Польск. яз.

17. Leszkowicz T. Nowa Huta: historia, mit, rzeczywistość, 2014 [Электронный ресурc]. URL: http://histmag.org/ Nowa-Huta-historia-mit-rzeczywistosc-9629 (дата обращения: 24.10.2016). Польск. яз.

18. Budowa Pałacu Kultury i Nauki ruszyła 60 lat temu [Электронный ресурс]. URL: http://www.rp.pl/
artykul/869047-Budowa-Palacu-Kultury-i-Naukiruszyla-60-lat-temu.html\#ap-2 (дата обращения: 06.01.2017). Польск. яз.

19. Рудченко О. Дворец культуры и науки в Варшаве. 2001 [Электронный ресурс]. URL: http://www. projectclassica.ru/v_o/02_2001/02_о_08.htm (дата обращения: 19.02.2017).

20. Kielar A. Ann Applebaum: PKiN to symbol stalinizmu. 2013 [Электронный ресурс]. URL: http://www. politykawarszawska.pl/a/254 (дата обращения: 17.09.2016). Польск. яз.

21. Нендза-Щикониовска К.С. Восприятие архитектонических решений первых послевоенных лет в современном польском сознании [Электронный ресурс] // Молодежь и наука : сборник материалов IX Всероссийской научно-технической конференции студентов, аспирантов и молодых ученых с международным участием, посвященной 385-летию со дня основания г. Красноярска. Красноярск : Сибирский федеральный ун-т, 2013. URL: http://elib.sfu-kras.ru/ handle/2311/11006 (дата обращения: 17.09.2016).

\section{ARCHITECTURE OF THE POLISH PEOPLE'S REPUBLIC AS A REFLECTION OF POLITICAL IDEAS}

\section{EVGENIA M. KUZYURINA}

Pitirim Sorokin Syktyvkar State University, 55, Oktyabrsky Av., Syktyvkar, Komi Republic, 167001, Russia E-mail: evgeniya.kuzurina@gmail.com

\footnotetext{
Abstract. The article proposes to consider the conception of architecture as a way of presentation of political ideas through aesthetic categories, basing on the analysis of the socialist constructions: the Palace of Culture and Science in Warsaw and Nowa Huta (Kraków region). This article explores the functions of architecture in the presentation of the political ideology of the Polish People's Republic.

The issue of political engagement of art, including architecture, remains relevant at the present stage, when the problem of political manipulation is still widespread in society. The environment, organized by the architecture, is also constantly affects the emotions, the mind and human behavior. It is possible to transfer pre-programmed information through architectural structures.

The subject of the research demands the interdisciplinary approach. The methodological foundation of the research is going to base on the comparative, problem-chronological, semiotic methods, art and system analysis.

The article presents the architecture of the Polish People's Republic as a special socio-political space, easily re-encoded
}

according to the regime change. This can be noticed in the renaming of streets and squares, replacing the world's heroes by the national ones, etc. With the establishment of the communist regime in Poland, the principle of socialist realism was introduced into the culture; the art was subordinated to the needs of ideology and politics. The author explores the role of the architectural construction of the Polish People's Republic in the changes in the structure of society. The special attention is focused on the relation of the modern Polish society to the heritage of the communist era.

The author concludes that the architecture is a visual interpretation of the political reformations in the country and the most long-term symbol of the communist era political aesthetics.

Key words: aesthetics, politics, political aesthetics, socialist realism, architecture, Nowa Huta, the Palace of Culture and Science, socialist realism.

Citation: Kuzyurina E.M. Architecture of the Polish People's Republic as a Reflection of Political Ideas, $\mathrm{Ob}$ servatory of Culture, 2017, vol. 14, no. 2, pp. 240-246.

\section{References}

1. Ikonnikov A.V. Funktsiya, forma, obraz v arkhitekture [Function, Form, Image in Architecture]. Moscow, Stroiizdat Publ., 1986, 286 p.

2. Lunacharsky A.V. Vospominaniya i vpechatleniya. Lenin o monumental'noi propagande, 1933 [Memories and Impressions. Lenin about the Monumental Propaganda, 1933]. Available at: http://leninism.su/memory/4163vospominaniya-i-vpechatleniya.html?showall=\&start=19 (accessed 16.02.2017). 
3. Smith R.W., Bugni V. Teoriya simvolicheskogo interaktsionizma i arkhitektura [Symbolic Interaction Theory and Architecture], Sotsiologicheskie issledovaniya [Sociological Studies], 2010, no. 9, pp. 71-79.

4. Veselovskaya V. "Nowa Huta" v Krakove - (ne)zabytoe proshloe ili Pochemu populyarnyi sredi turistov iz ES raion ne poseshchayut zhiteli stran byvshego SSSR [["Nowa Huta” in Krakow - The (Un)Forgotten Past, or Why the Popular among EU Tourists Area Is Avoided by the People of the Former USSR], 2014. Available at: http://www.day. kiev.ua/ru/article/puteshestviya/nowa-huta-v-krakovenezabytoe-proshloe (accessed 02.12.2016).

5. Cegła E. Socrealizm Nowej Huty widzianyz "traban$t a$ " [The Socialist Realism of Nowa Huta], 2013. Available at: http://krakow.naszemiasto.pl/artykul/galeria/ socrealizm-nowej-huty-widziany-z-trabanta,1944421,t,id. html (accessed 02.02.2017).

6. Khan-Magomedov S.O. Arkhitektura sovetskogo avangarda. Kn. 2: Sotsial'nye problemy [The Soviet Avant-Garde Architecture. Book 2: the Social Problems]. Available at: http://www.alyoshin.ru/Files/publika/khan_archi/ khan_archi_2_037.html (accessed 10.10.2016).

7. Pavlovich V. Stroiteli Novoi Guty [The Builders of Nowa Huta], Smena [Shift]. Available at: http://smena-online.ru/sites/default/files/14__ 1953.pdf (accessed 10.10.2016).

8. Ikonnikov A.V. Arkhitektura XX veka: Utopii i real'nost'. T. 1 [The Architecture of the 20th Century. Utopia and Reality. Vol. 1]. Moscow, Progress-Traditsiya Publ., 2001, $669 \mathrm{p}$.

9. Istoriya "stalinskikh" vysotok i ee prodolzhenie. Foto. Ch. 1. [The History of "Stalinist" Skyscrapers and its Continuation. Photo. Part 1], 2007. Available at: http://www.archdesignfoto.com/istoriya-stalinskix-vysotok-i-ee-prodolzhenie-foto-chast-1.html (accessed 6.02.2017).

10. Strelbitskaya M. Varshava. Shestiletnii plan rekonstruktsii 1950-1955 gg. [Warsaw. The Six-Year Plan of Reconstruction of 1950-1955], Sovetskaya arkhitektura [Soviet Architecture]. Available at: http://www.sovarch.ru/104/ (accessed 02.02.2017).

11. Tsirankevich Yu. Pol'sha na putyakh k sotsializmu [Poland on the Road to Socialism], Ogonek [Little Flame], 1950, no. 39, pp. 4-5.

12. Strelbitskaya M.V. Dvorets Kul'tury i Nauki v Varshave (Pałac Kultury i Nauki) [The Palace of Culture and Science in Warsaw], Sovetskaya arkhitektura. Ob"ekty [Soviet Architecture. The Objects]. Available at: http://www. sovarch.ru/catalog/object/234/?photo $=5$ (accessed 25.11.2016).

13. Arkhitektura i politika. (Interv'yu s doktorom politicheskikh nauk, professorom M.Yu. Urnovym) [Architecture and Politics. (The Interview with Doctor of Political Sciences, Prof. M.Yu. Urnov)], Polit.ru: informatsionno-analiticheskii kanal [Polit.ru: the Information and Analytical Channel], 2010. Available at: http://polit.ru/ article/2010/08/24/architechture/1347867610000/ (accessed 02.02.2017).

14. Łaszkiewicz M. O Nowej Hucie stów kilka. Powstanie i rozwój dzielnicy [Few Words about Nova Huta. The Emergence and Development of the Area], 2011. Available at: http://www.konflikty.pl/historia/czasy-najnowsze/onowej-hucie-slow-kilka-powstanie-i-rozwoj-dzielnicy/ (accessed 24.10.2016).

15. Syska K. Kul'tura, nostal'giya, intelligentsiya: pol'skii opyt [Culture, Nostalgia and Intellectuals: the Polish Experience], Intelros - intellektual'naya Rossiya: Mezhdunarodnyi zhurnal issledovaniya kul'tury [Intelros - Intellectual Russia: the International Journal of Cultural Studies], 2015, no. 4. Available at: http://www.intelros. $\mathrm{ru} /$ readroom/nz/n4-2015/28090-kultura-nostalgiyaintelligenciya-polskiy-opyt.html (accessed 22.11.2016).

16. Nowa Huta - dzieło polskiego socrealizmu [Nowa Huta - the Case of the Polish Socialist Realism], 2014. Available at: http://www.polskieradio.pl/39/156/ Artykul/1154281,Nowa-Huta-\%E2\%80\%93-dzielopolskiego-socrealizmu (accessed 24.10.2016).

17. Leszkowicz T. Nowa Huta: historia, mit, rzeczywistość [Nowa Huta: History, Myth, Reality], 2014. Available at: http://histmag.org/Nowa-Huta-historia-mitrzeczywistosc-9629 (accessed 24.10.2016).

18. Budowa Pałacu Kultury i Nauki ruszyła 60 lat temu [The Construction of the Palace of Culture and Science Started 60 Years Ago]. Available at: http://www.rp.pl/ artykul/869047-Budowa-Palacu-Kultury-i-Naukiruszyla-60-lat-temu.html\#ap-2 (accessed 06.01.2017).

19. Rudchenko O. Dvorets kul'tury i nauki v Varshave [The Palace of Culture and Science in Warsaw], 2001. Available at: http://www.projectclassica.ru/v_o/02_2001/02_o_08. htm (accessed 19.02.2017).

20. Kielar A. Ann Applebaum: PKiN to symbol stalinizmu [Ann Applebaum: the Palace of Culture and Science Is a Symbol of Stalinism], 2013. Available at: http://www. politykawarszawska.pl/a/254 (accessed 17.09.2016).

21. Nendza-Shchikoniovska K.S. Vospriyatie arkhitektonicheskikh reshenii pervykh poslevoennykh let $\mathrm{v}$ sovremennom pol'skom soznanii [The Perception of Architectonic Solutions of the First Post-War Years in the Modern Polish Consciousness], Molodezh' i nauka: sbornik materialov IX Vserossiiskoi nauchno-tekhnicheskoi konferentsii studentov, aspirantov i molodykh uchenykh s mezhdunarodnym uchastiem, posvyashchennoi 385-letiyu so dnya osnovaniya g. Krasnoyarska. Krasnoyarsk, Sibirskii Federal'nyi Universitet [Youth and Science: the Proceedings of the 9th All-Russian Scientific-Technical Conference of Students, Postgraduates and Young Scientists with International Participation, Dedicated to the 385th Anniversary of the Foundation of the City of Krasnoyarsk. Krasnoyarsk, Siberian Federal University], 2013. Available at: http://elib.sfu-kras.ru/ handle/2311/11006 (accessed 17.09.2016). 